\title{
Effects of RMI 12,936, a synthetic antiprogestational steroid, on the oestrous cycle and ovulation in the rat
}

\author{
K. E. Kendle, J. R. Paterson and Catherine A. Wilson* \\ School of Pharmacy, Robert Gordon's Institute of Technology, Schoolhill, Aberdeen AB9 IFR, \\ and \\ * Department of Physiology, The Royal Veterinary College, Royal College Street, \\ London NWI OTU, U.K.
}

\begin{abstract}
Summary. RMI 12,936 inhibited the vaginal cycle and ovulation in the rat. This effect was not mimicked by oestrogen and was partly reversed by progesterone. Ovulation was restored by injection of hCG and the inhibition was associated with reduced cyclic and tonic $\mathbf{L H}$ secretion while hypophysial LH levels were generally unaffected. Hypophysial sensitivity to LH-RH was reduced compared with that when ovulation was blocked with sodium pentobarbitone. It is concluded that RMI 12,936 blocks ovulation by causing a reduction in hypophysial sensitivity to $\mathrm{LH}-\mathrm{RH}$ and that this is probably an antiprogestational effect.
\end{abstract}

\section{Introduction}

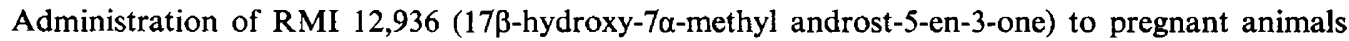
produces antifertility effects and much of the work reported previously has been aimed at elucidating the mechanisms of these effects. RMI 12,936 inhibits progesterone synthesis while its metabolite(s) have other antifertility effects which may include antagonism of progesterone at the receptor level (Kendle, 1975, 1976, 1978; Grunwell, Benson, Johnston \& Petrow, 1976; Hardy, Kendle, Lawrie \& Omand, 1977). The facilitative role of progesterone in ovulation has been recognized for many years (Everett, 1940; Everett \& Sawyer, 1949) and has been shown to be mediated through effects on the medial preoptic and suprachiasmatic areas (Bishop, Kalra, Fawcett, Krulich \& McCann, 1972). Inhibitors of progesterone synthesis have also been shown to inhibit ovulation (Lipner \& Greep, 1971) and removal of endogenous sources of progesterone in immature PMSG-treated rats inhibited the LH surge which was restored by exogenous progesterone (Wilson, Gilbert, Hadley \& McNeilly, 1977). The effects of the antiprogestagen RMI 12,936 on the oestrous cycle and ovulation have therefore been investigated.

\section{Materials and General Methods}

SPF-derived rats of the Sprague-Dawley strain were used at the School of Pharmacy, Robert Gordon's Institute, and are described in this paper as RGI rats, while rats of the same strain used in the Royal Veterinary College are identified as VET rats. RGI rats were housed as described previously (Kendle, 1975) with artificial illumination from 08:00 to 20:00 h daily; VET rats were housed similarly but with artificial illumination from 06:00 to 20:00 h.

Steroids (purchased from BDH (Chemicals) Ltd, Poole, except for RMI 12,936, a gift from Merrell National Laboratories) were suspended in the aqueous vehicle containing $0.25 \%(\mathrm{w} / \mathrm{v})$ sodium carboxymethylcellulose and 1\%(w/v) 'Tween 80'; hCG (Pregnyl: Organon) and synthetic LH-RH (Hoescht U.K. Ltd, Hounslow, Middlesex) were dissolved or diluted in saline $(0.9 \%(\mathrm{w} / \mathrm{v})$ sodium chloride solution) before use. Doses were administered subcutaneously in a dose volume of $0.5 \mathrm{ml}$ except when otherwise stated. When appropriate, vaginal lavages were taken daily and only 
rats showing at least 2 regular 4-day oestrous cycles were used in the experiments. The day of prooestrus was designated Day P and that of oestrus Day O; days of dioestrus were Days D1 and D2.

Ovulation was detected by macroscopic and microscopic examination of the oviducts to reveal the presence of eggs in the distended ampulla. Facilities were not available for histological examination of the ovaries.

LH assay was carried out at the Royal Veterinary College. Serum LH concentrations were measured in triplicate by the double-antibody radioimmunoassay described by Naftolin \& Corker (1971); the LH standard, LER-C ${ }_{2}-1056$, was provided by Dr L. Reichert and the antibody to LH was provided by Dr G. Niswender. The least detectable amount of $\mathrm{LH}$ in this assay was $20 \mathrm{pg}$ LER- $\mathrm{C}_{2}-1056$ (potency 1.73 times NIH-LH-S1) and the intra- and inter-assay coefficients of variation were 11 and $16 \%$ respectively. The LH measurements were for $10 \mu \mathrm{l}$ samples from blood collected on Day P and for $100 \mu$ samples from blood taken on Day D2.

The same method was used for the measurement of hypophysial LH after showing that blanks consisting of saline or hypothalamic tissue homogenized in saline contained no detectable activity and that hypophysial LH dilution curves were not significantly different in gradient from standard curves.

For clarity of presentation details of the individual experimental designs are given in the 'Results'.

\section{Results}

\section{Effect on the oestrous cycle}

Mature female RGI rats (5/group) were given vehicle, $2 \mathrm{mg}$ or $0.2 \mathrm{mg}$ RMI 12,936 on Day $P$ and vaginal smears were taken daily for 22 consecutive days. The animals were then killed and their ovaries and adrenal glands were removed and weighed to the nearest $0 \cdot 1 \mathrm{mg}$.

Control animals given the vehicle continued to show regular 4-day oestrous cycles while those given 2 mg RMI 12,936 showed oestrous smears (100\% cornified cells) on the day after dosing and smears characteristic of dioestrus (predominantly leucocytes) thereafter. The animals given $\mathbf{0 . 2} \mathrm{mg}$ RMI 12,936 showed erratic cycles with periods of oestrus ranging from 1 to 11 days separated by periods of dioestrus ranging from 1 to 12 days.

Mean \pm s.e.m. ovarian weights at autopsy were $83 \cdot 5 \pm 4 \cdot 1,64 \cdot 1 \pm 3.8$ and $67 \cdot 1 \pm 2.6 \mathrm{mg}$ in the control, $2 \mathrm{mg}$ - and $0.2 \mathrm{mg}$-treated rats respectively, and analysis of these data in a Fisher multiplerange test showed that the differences were not significant $(P>0.05$ for all contrasts). Mean adrenal weights were unaffected by treatment, the values being $69 \cdot 5,66 \cdot 3$ and $69 \cdot 4 \mathrm{mg}$ respectively, but while the control values were grouped very closely round the mean (s.d. 1.86) the range of values in the treated animals was much greater (s.d. 10.44 and 9.29).

\section{Effect on ovulation after treatment at pro-oestrus}

RGI rats (5/group) were treated with the vehicle, $2 \mathrm{mg}$ RMI 12,936 or $0.2 \mathrm{mg}$ RMI 12,936 at 12:00 h on Day P. At autopsy between 09:00 and 11:00 h the next day all animals had ovulated and there were no significant differences between the mean numbers of eggs shed or mean ovarian weights. A similar experiment in VET rats showed that administration of $5 \mathrm{mg}$ RMI 12,936 at 13:00 $\mathrm{h}$ or 17:00 $\mathrm{h}$ on the day of pro-oestrus also failed to block ovulation at oestrus the following day.

In a further experiment, RGI rats (5/group) were given the vehicle, $2 \mathrm{mg}$ RMI 12,936 or $0.2 \mathrm{mg}$ RMI 12,936 at 12:00 h on Day P. The animals were killed 5 days later when the vaginal smears of the control animals indicated oestrus. All of the control animals had ovulated ( $14 \pm 0.71 \mathrm{eggs} / \mathrm{rat})$, but none of the treated animals had ovulated and the mean \pm s.e.m. ovarian weights of the treated animals $(69.2 \pm 3.2 \mathrm{mg}$ for the $2 \mathrm{mg}$ dose and $60.5 \pm 2.4 \mathrm{mg}$ for the $0.2 \mathrm{mg}$ dose) were significantly $(P<0.05)$ lower than that of the control animals $(83.0 \pm 4.0 \mathrm{mg})$ (Fisher multiple range test).

\section{Effect on ovulation after administration on Day D2}

Groups of VET rats were given various doses of RMI 12,936 or oestradiol benzoate as shown in Table 1 at 17:00 h on Day D2. The results show that RMI 12,936 caused a dose-related reduction 
in the number of animals ovulating while high doses of oestradiol did not. Mean numbers of eggs per animal ovulating were unaffected by either treatment.

Table 1. Effect on ovulation in the rat of administration of RMI 12,936 and oestradiol benzoate at 17:00 $\mathrm{h}$ on the last day of dioestrus

\begin{tabular}{clccc}
\hline Compound & $\begin{array}{c}\text { Dose } \\
(\mathrm{mg} / \mathrm{rat})\end{array}$ & $\begin{array}{c}\text { No. } \\
\text { of rats }\end{array}$ & $\begin{array}{c}\text { No. } \\
\text { ovulating } \\
(\%)\end{array}$ & $\begin{array}{c}\text { Mean no. of ova } \\
( \pm \text { s.e.m. }) / \text { ovulating } \\
\text { rat }\end{array}$ \\
\hline RMI 12,936 & 0.25 & 9 & $6(66)$ & $11 \cdot 2 \pm 2 \cdot 2$ \\
& 0.5 & 10 & $5(50)$ & $11 \cdot 0 \pm 1 \cdot 6$ \\
& 1.0 & 7 & $3(43)$ & $12 \cdot 6 \pm 1 \cdot 8$ \\
Oestradiol & $2 \cdot 0$ & 10 & $1(10)$ & $12 \cdot 0$ \\
benzoate & 0.002 & 4 & $3(75)$ & $9 \cdot 8 \pm 1 \cdot 5$ \\
\hline
\end{tabular}

\section{Reversal of inhibition of ovulation}

Twenty (20) VET rats were given 2 mg RMI 12,936 at 17:00 h on Day D2 and 10 rats were then treated with $2 \mathrm{mg}$ progesterone at 17:00 h on Day P. At autopsy, 1 of the RMI 12,936-treated and 4 of the RMI 12,936 + progesterone-treated rats had ovulated. The difference was not significant $(P=0 \cdot 303$, Fisher Exact test).

In another experiment, VET rats were given RMI 12,936 or RMI 12,936 + progesterone as before except that the progesterone was given at 13:00 h on Day P. None of the 9 RMI 12,936treated rats ovulated while 10 of the $18 \mathrm{RMI} 12,936$ + progesterone-treated rats did so. The difference was significant $(P=0 \cdot 01$, Fisher Exact test). Mean ( \pm s.e.m.) ovarian weight in the progesteronetreated animals was higher than in those given RMI 12,936 alone $(90.7 \pm 3.4 \mathrm{mg}$ versus $78.6 \pm 6.4$ $\mathrm{mg}, P=0.05$, Student's $t$ test). Analysis of ovarian weights from all animals ovulating compared to all animals not ovulating showed a similar difference $(94.2 \pm 3.0 \mathrm{mg}$ versus $82.2 \pm 4.5 \mathrm{mg}, P=0.05$, Student's $t$ test).

In a third experiment groups of 5 RGI rats were treated with the vehicle (Groups 1 and 2) or 2 mg RMI 12,936/rat (Groups 3, 4 and 5) on Day D2, and then with vehicle (Groups 1 and 3), 10 i.u. hCG (Groups 2 and 4) or 5 i.u. hCG (Group 5) on Day P. The animals were killed between 09:00 and 11:00 h on Day $O$ and the numbers of eggs in the oviducts were counted and the ovaries weighed. Administration of hCG reversed the inhibition of ovulation produced by RMI 12,936. All the rats in Groups 1, 2, 4 and 5 ovulated; none did so in Group 3. There was no significant difference in the numbers of eggs recovered $(P>0.05)$ and the ovarian weights did not differ significantly.

\section{Inhibition of gonadotrophin secretion}

RGI rats (5/group) were subjected to sham unilateral ovariectomy and administration of the vehicle (Group 1), unilateral ovariectomy and vehicle administration (Group 2) or unilateral ovariectomy and administration of a single dose of $2 \mathrm{mg}$ RMI 12,936 (Group 3). After 12 days the animals were killed, and the right ovaries were removed and weighed to the nearest $0.1 \mathrm{mg}$. Mean \pm s.e.m. weights were $35 \cdot 6 \pm 2 \cdot 2,58 \cdot 3 \pm 2 \cdot 5$ and $28 \cdot 4 \pm 2 \cdot 0 \mathrm{mg}$ for Groups 1,2 and 3 respectively (Group 2 versus Group 1, $P=0.01$; Group 3 versus Group 1, $P>0.05$, and versus Group 2, $P=$ 0.001).

In another experiment RGI rats were given the vehicle (20 rats) or 2 mg RMI 12,936 (20 rats) at 17:00 h on Day D2. The following day (pro-oestrus) 5 animals from each group were anaesthetized with sodium pentobarbitone and blood samples (approximately $1 \mathrm{ml}$ ) were withdrawn by cardiac puncture from each animal at 17:30,18:30, 19:30 and 20:30 h. After withdrawal of 2 samples $2 \mathrm{ml}$ saline $(0.9 \% \mathrm{NaCl})$ was given intravenously to replace the fluid lost. The remaining animals in each group were killed at 16:00, 17:00 or 18:00 h when blood samples were collected and the pituitary 
glands were removed. Serum LH was determined. Pituitary glands were homogenized in $1 \mathrm{ml}$ saline $(0.9 \% \mathrm{NaCl})$, centrifuged at $800 \mathrm{~g}$ for $10 \mathrm{~min}$ and the $\mathrm{LH}$ content of the supernatant, diluted 1 in 1000 , was determined. The serum LH peak observed in control animals was absent in the RMI 12,936-treated animals (Table 2) and hypophysial LH content was significantly altered only by treatment at 18:00 $\mathrm{h}$ (Table 3).

Table 2. Serum LH levels (mean \pm s.e.m.) in rats killed or bled at various times on Day P after treatment with $2 \mathrm{mg}$ RMI 12,936/rat at 17:00 $\mathrm{h}$ on Day D2

\begin{tabular}{ccc}
\hline & \multicolumn{2}{c}{ Serum LH (ng/ml) } \\
\cline { 2 - 3 } Time of sample (h) & Treated rats* & Control rats \\
\hline $16: 00$ & $1.03 \pm 0.41$ & $8.08 \pm 1.68$ \\
$17: 00$ & $2.05 \pm 1.07$ & $21.48 \pm 11.05$ \\
$17: 30$ & $0.57 \pm 0.24$ & $27.04 \pm 6.84$ \\
$18: 00$ & $3.36 \pm 1.84$ & $17.34 \pm 12.73$ \\
$18: 30$ & $0.47 \pm 0.24$ & $5.74 \pm 1.57$ \\
$19: 30$ & $0.82 \pm 0.36$ & $3.68 \pm 1.17$ \\
$20: 30$ & $0.98 \pm 0.60$ & $2.65 \pm 0.40$ \\
\hline
\end{tabular}

* All these values significantly lower than the maximum value for the control rats $(P<0.01$, Fisher multiple range test $)$.

Table 3. Hypophysial LH content (mean \pm s.e.m.) at autopsy on Day $P$ in rats given $2 \mathrm{mg} / \mathrm{RMI} 12,936$ at $17: 00 \mathrm{~h}$ on Day D2

\begin{tabular}{llll}
\hline \multirow{2}{*}{$\begin{array}{c}\text { Time of autopsy } \\
(\mathrm{h})\end{array}$} & \multicolumn{2}{c}{ Hypophysial LH $(\mu \mathrm{g})$} & \\
\cline { 2 - 3 } & Treated rats & Control rats & Significance* \\
\hline $16: 00$ & $20.78 \pm 6.22$ & $19.64 \pm 6.17$ & N.S. \\
$17: 00$ & $22.04 \pm 12.50$ & $11.98 \pm 3.28$ & N.S. \\
$18: 00$ & $14.26 \pm 1.24$ & $20.63 \pm 1.97$ & $P<0.05$ \\
All results & $19.02 \pm 4.42$ & $17.58 \pm 2.68$ & N.S. \\
\hline
\end{tabular}

* Analysis after logarithmic transformation to satisfy requirements of $t$ test.

In a third experiment, 4 RGI rats were each given $2 \mathrm{mg} \mathrm{RMI} \mathrm{12,936} \mathrm{at} \mathrm{15:00} \mathrm{h} \mathrm{on} \mathrm{Day} \mathrm{D1} \mathrm{and}$ 4 rats were given the vehicle. The animals were killed $24 \mathrm{~h}$ later on Day D2 and LH levels in the serum and pituitary glands were determined. Total hypophysial LH was not significantly changed by treatment $(4.65 \pm 1.00$ versus $6.1 \pm 1.52 \mu \mathrm{g} /$ gland $)$ but serum levels were markedly reduced $(0.15 \pm 0.03$ versus $3.28 \pm 0.89 \mathrm{ng} / \mathrm{ml}, P<0.005$ after logarithmic transformation).

\section{Reversal of ovulation inhibition with $\mathrm{LH}-\mathrm{RH}$}

RGI rats were given $2 \mathrm{mg}$ RMI 12,936 at 17:00 h on Day D2 or $35 \mathrm{mg}$ sodium pentobarbitone/kg intraperitoneally at 15:00 h on Day P and were then treated with $0.05,0.5$ or $5 \mu \mathrm{g} \mathrm{LH}-\mathrm{RH}$ or the vehicle at 16:00 h on Day P. The animals were killed at 09:00 h the next day and the numbers of animals ovulating were determined.

The results given in Table 4 show that the antiovulatory effect of RMI 12,936 is reversed by LH-RH administration but that the dose required is higher than that necessary to induce ovulation in rats treated with sodium pentobarbitone. 
Table 4. Numbers of rats ovulating (5/group) after treatment with LH-RH at 16:00 h on Day $P$ and RMI 12,936 at $17: 00 \mathrm{~h}$ on Day D2 or sodium pentobarbitone at $15: 00 \mathrm{~h}$ on Day $\mathrm{P}$

\begin{tabular}{llllll}
\hline & \multicolumn{3}{c}{ Dose of LH-RH $(\mu \mathrm{g})$} & & $\begin{array}{c}\text { Median effective } \\
\text { Treatment }\end{array}$ \\
\cline { 2 - 5 } & 5 & 0.5 & 0.05 & 0 & 0.5664 \\
\hline $\begin{array}{l}2 \text { mg RMI 12,936 of LH-RH }(\mu \mathrm{g}) * \\
\begin{array}{c}35 \text { mg sodium } \\
\text { pentobarbitone/kg }\end{array}\end{array}$ & 5 & 2 & 0 & 0 & 0.0575 \\
None & 5 & 5 & 2 & 0 & \\
\hline
\end{tabular}

* Calculated after logit transformation. Relative activity 0.1 , approximate fiducial limits 0.06 to $0.16(P=0.05)$.

\section{Discussion}

Administration of RMI 12,936 at pro-oestrus causes disruption of the ovarian cycle, as indicated by vaginal cytology, and complete inhibition of the cycle in rats given the higher dose. These effects persisted for at least 2 weeks. Similar treatment was shown to block ovulation provided that it was given at least 2 days before the time of expected ovulation, but administration at pro-oestrus failed to block ovulation on the following day. This may support the hypothesis that activity of the compound is due to a slowly formed metabolite (Kendle, 1978).

Oestrogen administered under similar conditions did not block ovulation, showing that the effect of RMI 12,936 was not due to its slight oestrogenic activity. Progesterone partly reversed the block to ovulation, indicating that the block may be due to the antiprogestational activity of RMI 12,936 or a metabolite. Investigations to elucidate the mechanism of the block showed that gonadotrophin secretion, as indicated by ovarian hypertrophy in hemicastrates, was inhibited while induction of ovulation by hCG indicated that the ovaries were capable of responding to gonadotrophin although their sensitivity was not determined. Assays of serum and hypophysial LH confirmed that there was inhibition of both tonic and cyclic LH secretion which was not associated with consistent hypophysial depletion. The sensitivity of RMI 12,936-treated rats to LH-RH was lower by a factor of 10 than the sensitivity of rats treated with sodium pentobarbitone.

It is therefore suggested that the effect of RMI 12,936 on ovulation in cyclic rats is a prevention of LH secretion by reducing hypophysial sensitivity to LH-RH. This effect may be due to the antiprogestational effects of RMI 12,936 or a metabolite because progesterone is known to increase sensitivity of the hypophysis to LH-RH (Aiyer \& Fink, 1974). This conclusion is based on investigations of the first post-treatment cycle and is not therefore necessarily applicable to the whole of the prolonged period of ovulation inhibition which follows a single dose of RMI 12,936.

We thank Dr V. Petrow and Merrell National Laboratories, Division of Richardson Merrell Inc., Cincinnati, Ohio, for the RMI 12,936, and Miss D. J. Baker, Hoechst U.K. Ltd, Hounslow for the LH-RH.

\section{References}

AIYER, M.S. \& FINK, G. (1974) The role of sex steroid hormones in modulating the responsiveness of the anterior pituitary gland to luteinizing hormone releasing factor in the female rat. $J$. Endocr. 62, 553-572.

Bishop, W., Kalra, P.S., Fawcert, C.P., Krulich, L. \& MCCANN, S.M. (1972) Effects of hypothalamic lesions on the release of gonadotrophins and pro- lactin in response to oestrogen and progesterone treatment in female rats. Endocrinology 91, 1404 1410.

EVERETT, J.W. (1940) Restoration of ovulatory cycles and corpus luteum function in persistent-estrus rats by progesterone. Endocrinology 27, 681-686.

Everett, J.W. \& SAWYer, C.H. (1949) A neural timing factor in the mechanism by which progesterone 
advances ovulation in the cyclic rat. Endocrinology 45, 581-595.

Grunwell, J.G., Benson, H.D., Johnston, J.O. \& Petrow, V. (1976) Antiprogestational agents. The synthesis of 7-alkyl steroidal ketones with antiimplantational and antidecidual activity. Steroids 27, 759-771.

Hardy, D.G., Kendle, K.E., Lawrie, M.R. \& Omand, H.E. (1977) The effect of RMI 12,936, a synthetic antiprogestational steroid, on ovarian steroidogenesis in the rat. J. Reprod. Fert. 49, 231-235.

KENDLE, K.E. (1975) Some biological properties of RMI 12,936 , a new synthetic antiprogestational steroid. J. Reprod. Fert. 43, 505-513.

KENDLe, K.E. (1976) Effects of RMI 12,936, a synthetic antiprogestational steroid, in the rat. J. Reprod. Fert. 48, 159-166.

KENDLE, K.E. (1978) Further investigation of the antifertility effects in the rat of the antiprogestational steroid, RMI 12,936, and related compounds. $J$. Reprod. Fert. 52, 373-377.

LIPNER, H. \& GREEP, R.O. (1971) Inhibition of steroidogenesis at various sites in the biosynthetic pathway in relation to induced ovulation. Endocrinology 88, 602-607.

Naftolin, F. \& CoRker, C.S. (1971) An ultra-micro method for the measurement of luteinizing hormone by radioimmunoassay. In Radioimmunoassay Methods, pp. 641-645. Eds K. E. Kirkham \& W. M. Hunter. Churchill Livingstone, Edinburgh.

Wilson, C.A., Gilbert, D., Hadley, J.C. \& McNeilly, A.S. (1977) Influence of progesterone on the preovulatory luteinizing hormone surge in immature rats treated with pregnant mare serum. $J$. Endocr. 72, 24P-25P.

Received 12 December 1977 